\title{
Editors' Report-Perspectives on Politics: A Political Science Public Sphere
}

\author{
Jeffrey C. Isaac, Editor in Chief, with the assistance of James Moskowitz, \\ Managing Editor and Margot Morgan, Book Review Managing Editor
}

I am happy to report that Perspectives on Politics continues to thrive. In the Lroughly three-and-a-half years since we assumed editorial control of the journal, in June 2009, we have succeeded in strengthening journal operations and procedures and in projecting a new and growing excitement about Perspectives and the role it can play in contributing to the invigoration of the discipline.

We have a highly talented, energetic, and well-organized staff, and we have instituted and fine-tuned a strong set of procedures for dealing with authors, reviewers, and each other. As a consequence we have continued to work efficiently and stay on production schedule with Cambridge and the printers. I have received a great deal of positive feedback from authors and from readers about the journal, its quality, its special sections, and its accessibility and responsiveness. More importantly, we continue to receive a growing flow of manuscripts of an increasingly high quality, from "major" scholars eager to place their work in our journal and from more junior scholars who regard Perspectives and its mission as hospitable to their view of political science. In the past year we have published a wide range of authors from a variety of institutions.

In 2012 Perspectives published the APSA presidential address, 18 articles (with 33 authors and co-authors combined), 7 reflections essays (one coauthored), 6 book review essays, 8 book symposia (with 44 contributors), 9 critical dialogues, and 298 single-book or multiple-book reviews. We thus published the work of more than 400 political scientists. If you add to that the number of manuscript reviewers with whom we have corresponded, plus the number of authors submitting pieces that were not selected for external review, and the number of book review invitations declined, in 2012 the journal networked with over 1,00o political scientists. Through our extensive and substantive correspondence, and through the product of that correspondence-the journal itself-we believe we are succeeding in our goal of fostering a political science public sphere.

The Appendix to this report includes some basic publication and production data. We will be happy to answer any questions about this data to the best of our ability.

In what follows I would like briefly to outline a range of accomplishments worthy of note, which together help to explain our success thus far. In doing so, I will reiterate some of the themes of last year's report, since they are essential to our ongoing operations, and also since each year new members join the Council, and my goal is to keep every member of the Council maximally informed about our journal operations.

1. Perspectives is a collaborative effort, and the journal works well because it has a terrific staff. James Moskowitz is an exceptional Managing Editor. He combines business experience, strong communication and computer skills, a real aesthetic sensibility, and the scholarly perspective of an advanced and published political science PhD student. James has contributed immeasurably to the success of the journal along every dimension, from the efficient operation of the Editorial Manager system to the journal's terrific new design, and he is responsible for the extraordinary covers we have featured in the past year. James works full-time on the journal. In July of 2010 Margot Morgan became the full-time Book Review Managing Editor. Margot has worked with me (along with James) on the journal since I first became Book Review Editor eight years ago, and she had been serving as the point person regarding copy-editing and production of the Review section. When she received her PhD from Rutgers in 2010 she was promoted to a full-time position, enabling me to focus more attention on further improving the "front end" of the journal (and also to return part-time to the classroom, as per my agreement with IU).

James and Margot are a terrific team, and I could not do my job without their active involvement. They are joined by five, equally terrific Editorial Assistants whose contributions far exceed the 20 hours of work per week that their assistantships entail. Brendon Westler and Laura Bucci work on the journal's front end, reading every article submitted for publication, and participating with James and me in weekly "conference reviews" where we decide which pieces to send out for external review. They then divide up labor to find reviewers for the manuscripts and to stay on top of all communication with reviewers. They also work closely with James to prepare for publication those articles eventually accepted for publication. Emily Hilty, Peter Giordano, and Rafael Khachaturian work with Margot on the Review section, helping me find reviewers for each book, corresponding with reviewers, and working to move all reviews to publication. The staff works very well together. We meet weekly to discuss all aspects of the journal, to prepare manuscripts for copyediting, and to plan ahead. Adrian Florea, an experienced associate who will return to our staff next year when the term of his dissertation fellowship expires, also participates in our discussions. We also typically have lunch (supplied by me). It is a very upbeat work environment. All Editorial Assistants are encouraged to take initiative and to make sure that their work on the journal complements their academic work and long-term scholarly plans. And I subsidize every staff member (approximately $\$ 500$ per person) so that the entire staff can attend the annual MPSA meeting and participate in our editorial board meeting. Much of the work of academic journals is done by staff, almost all of whom are graduate assistants. I am very proud of my staff and proud of the work environment we have cultivated in our office.

2. The journal has a terrific editorial board. We stay in fairly regular communication with the board as a whole, and communicate very often with individual board members, to consult on difficult decisions and to seek additional reviews 
of manuscripts when this becomes necessary. Board members have been very responsive and helpful, and many of them have been proactive in encouraging authors to submit their work for review. I believe that a journal like Perspectives can succeed only if a diverse group of excellent and highly respected political scientists is willing to make a commitment, and if the individual scholars who compose that group are willing to link their credibility to the credibility of the journal. Sustaining this kind of connection has been an important accomplishment and it remains an ongoing commitment.

I am proud to say that the entire board that began with my tenure continues to serve, along with some newer and equally exceptional colleagues (a full list of our board members appears on our masthead and is included in the Appendix).

When we took over the journal, I instituted a policy that was neither required by APSA rules nor practiced by any other top journal of which I am aware: that members of the editorial board could not publish articles or essays in the journal. The reason for this was simple: we wanted to be as emphatic as possible about the seriousness of our review processes, and it was important that the journal in no way seemed to be a venue for its principal supporters. It was a great sacrifice for our board members to agree to this condition. And yet they did so as a matter of principle, helping to review other work while withholding from the journal important work of their own that unsurprisingly fit well with the journal's editorial mission.

Last year, after consultation with APSA staff, my own staff, and with the board itself, I decided to change the policy, and to open the pages of the journal to editorial board members. Our September 2012 issue featured a book symposium organized by board member Henry Farrell (Henry functioned as an editor, and he contributed to this symposium only by composing the editor charge to participants). The March 2013 issue of the journal is the first to contain Reflections essays by two board members, Daniel Drezner and Dara Strolovitch, both of whom have been very active on the board. One of our board members is currently revising an article submission for resubmission; the piece was rigorously externally reviewed on the first round, and will be so reviewed on the second round. The piece is excellent, and if all goes well, this will eventually be the first research article published by a board member in recent years.

In the coming years we will continue to expand our board, and will also continue to feature the writings of board members. Like all of our submissions, this work will be properly vetted according to our standard operating procedures.

3. We have excellent working relationships with APSA (especially Michael Brintnall and Polly Karpowicz), Cambridge University Press (especially Mark Zadrozny, Michael Marvin, and Jonathan Geffner, who is the Cambridge point person on all production issues), Beljan (printers), and AIRES, which runs the Editorial Manager system. James has done an excellent job in staying in touch with all of these people, being responsive to their concerns, and obtaining their help when it is necessary. I can't say enough about the synergy between Cambridge and APSA and how essential this kind of relationship is to the success of the journal. We are also fortunate to have the help of three excellent copy-editors: Linda Lindenfelser, who worked with Jim Johnson when the journal was at Rochester, Phyllis Berk, and Amy Perlow. While we do some copy-editing inhouse-many of the book review essays are copy-edited by Margot Morgan-we have budgeted to have almost all of it done externally by experienced professionals. This is important for a journal in which broad intelligibility, and thus excellent prose writing, is essential.

We are also very fortunate to have the exceptional support provided by Indiana University, its College of Arts and Sciences, and its political science department. IU provided course release for me and support for graduate assistants for the four years of my tenure as Book Review Editor. It also housed our editorial office and furnished state-of-the-art computer support. It is committed to continuing this support for the duration of my tenure as Editor in Chief of the journal (the only change is that IU has tripled our office space since we took over the entire journal). This means that for 10 years IU will have supported and housed the journal. This support, and the scholarly and collaborative spirit in which it is provided, has been indispensible to the success of Perspectives. In an age where such support is increasingly hard to come by, this is worth noting.
In October 2012 the journal moved into a terrific new suite of offices in Woodburn Hall, in the location that formerly housed the political science department's data lab. This is an exciting development that has greatly enhanced our work. The transition was a challenge, since we needed to vacate our old space in May of 2012, which meant that for over four months we shared our space with data lab personnel. I am happy to report that we are now firmly ensconced in our new space.

4. We have maintained excellent and efficient communication with authors, reviewers, and people in the field more generally. We try-and almost always succeed-in completing our internal review of each submitted research article within 7-10 days of submission. We move promptly to identify external reviews for all suitable manuscripts. I also write substantial and constructive letters to every author whose paper we decide not to send out for review. I try to send these letters within 10-14 days of submission, and when there are delays, I try to explain them to authors in personal letters. I have received a great deal of appreciative feedback from many of the authors whose papers we chose not to send out for external review. We also stay in close touch with authors through the publishing process, from external review through revision through preparation for publication. I write careful, clear, and substantive letters to each author offering guidance. If there are delays we write to authors explaining them. I write follow-up letters to authors from whom we really wish to see a revised paper, encouraging prompt revision and resubmission. I also write often to scholars in the field, inquiring about interesting-sounding conference presentations and inviting article submissions. I am especially interested in cultivating connections with junior scholars whose work has merited official recognition or seems particularly interesting. We are always looking to reach out to new authors and readers, and to attract new and exciting work for review and publication. At the same time, all research articles are subject to our strict, double-blind external-review process.

As a matter of general policy, we prize efficient, prompt, and kind communication. Every letter is an opportunity to explain the journal's distinctive mission and to make a friend for the journal. We also keep excellent records of 
all communication. Every official letter is sent through Editorial Manager, and copied to the Perspectives e-mail account and my own e-mail account, and all letters are backed up. In the spring of 2011 I made every letter available to the APSAappointed performance review committee, and was proud to do so, so that our operations remain fully transparent.

5. New Editorial Philosophy and Policies: The March 2010 issue contained a special section featuring an Editor Statement on Philosophy and Policy (included here as an Appendix). This Statement now appears at the beginning of each issue of the journal, right after the Editor Introduction. This text, and revised policies, have also been posted online at the Perspectives website. We are doing everything possible to explain and to publicize journal policies. This is in tune with our decision to "brand" the journal as A Political Science Public Sphere (itself explained in the Editor Statement).

6. In particular, we are working hard to make clear to all readers that every single research article published in Perspectives has been through a demanding, blind internal-review process and then a double-blind external-review process. Our review process-which includes careful editorial selection of reviewers and directions to all authors regarding revisions, and also includes very careful line-editing of every sentence by the Editor in Chief, in addition to careful copyediting-is as serious, if not more serious, than that of any other peer-reviewed political science journal.

I am happy to report that we continue to receive a growing number of excellent article submissions, many of which, it turns out, are authored by top scholars in the field. By being very serious about our review process, we hope to continue to increase the number of truly excellent articles submitted, and over time to continue to build the journal's reputation as a peer-reviewed journal, so that increasing numbers of junior colleagues think of Perspectives as a first option for their best work when this work is framed broadly, and so that departmental personnel and tenure and promotion committees will accord peer-review research articles published in Perspectives the measure of recognition they are due.

Along these lines, I am especially happy to report that the journal has built a very strong queue of accepted articles. Our June
2013 issue is in press, and our September and December 2013 article sections are already nearly filled with accepted articles (we currently have 10 articles accepted for these issues, and expect to have at least 15 articles in hand by our June printer deadline for the September issue). This queue is growing, and it speaks volumes for the journal moving forward.

7. Journal Thematic Focus: As we have reported in the past, we have become adept at developing a reasonable publication schedule that provides a measure of focus to our planned issues. Our June 2012 issue thus featured a wide range of articles, essays, and reviews on the theme of "New Approaches to the Study of Violence." And our September 2012 issue was a long-planned, 1oth anniversary issue on the theme of "Post-Katrina New Orleans and the Politics of Reconstruction." These issues have received a great deal of positive feedback from colleagues, and our September issue garnered extensive attention in the blogosphere and was indeed featured by Melissa Harris-Perry on her MSNBC television show. More importantly, these issues feature excellent political science research and writing. Our March 2013 issue, featuring the theme of "The Politics of Inequality in the Face of Financial Crisis," promises to be the best theme-centered issue we have published thus far. And our June 2013 issue, featuring the theme of "Nature and Politics," is currently in press. We will continue to develop theme-centered issues, though for a variety of reasons we will probably publish only one such issue annually in the coming years.

We are a general journal of political science, and the articles we publish represent the best of what is submitted to us that makes it through our review process. But by thinking strategically about timing and production schedules, proactively soliciting "Reflections" essays, and developing special Book Review theme sections, we are able to call attention to some of the "big topics" that touch on all areas of political science-as it is our mission to do. I regard this kind of editorial "visioning" and planning as a central aspect of my job as Editor in Chief of this particular journal. The themes that I decide to feature are developed on the basis of my own extensive reading, conversations with board members and other colleagues, and extensive staff deliberations. At the same time, I am always listening to and indeed soliciting feedback, from editorial board members and from colleagues more generally, about what we are doing, about themes that are worthy of attention, and about how we can do what we do better.

8. Special Review Formats and Sections: Perspectives seeks to nurture a political science public sphere that allows scholars to move beyond their normal comfort zones and reach broadly, beyond conventional methodological and subfield divides, to the discipline as a whole. Toward this end, in the past seven-anda-half years we have instituted a number of innovative formats to our Review section-book Symposia, Review Essays, Critical Dialogues, and creative categorizing of certain books. Indeed, this year we have decided to introduce a new format featuring review essays on important scholarly books from other disciplines, and to provocatively entitle these features "Undisciplined." (The rationale for these changes was explained in my March 2006 "Statement from the Book Review Editor," which is also included here as an Appendix, since our philosophy for the Book Review section has not changed, and indeed the perspectives laid out in that text anticipated what we are now trying to do with the journal as a whole.) Last year we added an additional innovation: each issue now contains, in addition to the "standard" four-subfield sections, a special "theme" section highlighting books that address an important substantive theme irrespective of field or approach. In recent issues we have featured the following themes in special sections: Religion and Politics; Violence and Politics; Authoritarianism, Elections, and Democracy?; Politics in the Face of Financial Crisis; and Nature and Politics. In addition, we did something unusual with our September 2012 issue as a way of highlighting the journal's distinctive mission and approach on its 1oth anniversary-we published only a special section featuring book reviews related broadly to the theme of "Post-Katrina New Orleans and the Politics of Reconstruction," and we broke out this special section into four subthemes: Minority Politics, Urban Politics, Disaster and Recovery, and Private Power/Public Power. In this issue, we published nine review essays, symposia, and critical dialogues combined; as well as reviews of 32 books in the special review section. 
We regard our innovation of a special Review section as an important development, of which we are proud. It is the outcome of conversations with scholars and leaders of APSA, as well as among ourselves, that have been going on ever since I became Book Review Editor in 2005. These conversations have focused on the intellectual and practical limits of the four-field framework that Perspectives inherited from the APSR (it is worth noting that this framework only evolved over time at the APSR), and whether or not Perspectives might and perhaps should reform this framework. This topic was discussed at my editorial board's inaugural 2009 meeting in Toronto, and the board expressed enthusiastic support for some sort of change. At our 2010 board meeting in Washington, DC, the board supported my proposal that the best way for our editorial team to address this issue, while still undertaking all the other changes noted above, would be for the journal to add a fifth section to the review, which would highlight a different substantive theme in each issue, rather than to modify the long-standing, inherited four-field format, which serves many functions in the profession.

It is worth underscoring that the overwhelming majority of the book reviews that we publish appear under one of the standard four subfield categories, and that while we have made important innovations in the Book Review section, the basic mission of the Review section remains unchanged: to publish careful, constructively critical, and interesting reviews of political science books that feature important scholarly research and writing.

It is also worth underscoring that every aspect of the Review section-its innovations and its more conventional features-is designed to serve our journal's core mission, which is the promotion of a political science public sphere. We believe that the book form represents an invaluable genre for the scholarly development of sustained, integrated analyses and arguments, and that scholarly books are thus an essential component of scholarly publishing. We thus seek to highlight the importance of political science books and to feature interesting discussions of books, in the hope that this will help sustain a book culture within political science and the social sciences more generally.

Indeed, one of our goals is to give full due to the entire range of genres and formats in which scholarly work in our discipline is published, from scholarly research articles and reflective essays to books, book reviews and review essays, and dialogues.

9. We are working hard to project the journal as an important site of serious thinking about the future and purpose of our discipline. My Editor Introductions to each issue, composed as titled, synthetic, and thematic essays, represent one part of this effort. Beyond those Introductions, I do a significant amount of writing intended to promote the journal. (This was the purpose of my essay on "What's the Value of Political Science?" published in the October 14, 2009 Chronicle Review; my piece "Perestroika and the Journals," which appeared in the October $2010 P S$ and my new essay "Political Science and Publicity," forthcoming in the June 2013 issue of Political Studies Review, a journal of the British Political Studies Association.)

More importantly, our desire to publicize and promote the journal is the reason we have instituted the practice of organizing a special Perspectives theme panel at every APSA Annual Meeting. In recent years these panels have featured editorial board members in roundtable discussions of important themes relevant both to the discipline broadly and to the editorial challenges and directions of the journal. Our inaugural panel, at the 2010 meeting in Washington, DC, was on the theme of "Perspectives on Subfields in Political Science." It featured Dan Drezner, Stathis Kalyvas, Paul Pierson, Dara Strolovitch, and Lisa Wedeen, with me serving as moderator. The panel was very well attended. (Our informal count put the number of attendees at around 10o.) In 2012 we planned a major panel around our special 1oth anniversary issue, but the panel was canceled, along with the entire New Orleans Conference. Our plan for 2013 is something new: the theme panel will focus on a discussion of our March issue on "The Politics of Inequality in the Face of Financial Crisis," and will feature seven authors discussing each others' work: Richard Boyd, Dan Drezner, Jacob Hacker, Margaret Kohn, Thomas Oately, Ben Page, and Dara Strolovitch.

The purpose of these panels is to call attention to important broad themes that transcend the normal conference designations; to foster the idea, and the practice, of the editorial board as a real intellectual community; and to provide a forum for serious intellectual discussion of the journal in which all interested colleagues can participate.

\section{SUMMARY}

To sum up, the journal is thriving, due to the terrific work of many fine people and the support offered by APSA, Cambridge, Indiana University, and especially by the colleagues who, as authors, reviewers, and readers, are our primary constituency. 


\section{PEER REVIEW APPENDIX}

Data on reviewing/manuscript success rates-2012 versus prior years

\section{2}

Total $(n=200)$

Do not externally review $\quad \mathbf{5 4 . 5 0} \%$

Review externally

$45.50 \%$

First decision upon external review

Decline $\quad \mathbf{5 2 \%}$

Major revision $\quad 33 \%$

Minor revision $\quad \mathbf{1 1 \%}$

Conditional accept $\quad 4 \%$

Final decision to date

Accept $\quad \mathbf{1 0 \%}$

Do not externally review $\quad 55 \%$

Decline upon review $\quad \mathbf{2 3} \%$

Revise $\quad \mathbf{6 \%}$

Under Review (V1-R1) $\quad 5 \%$

With Editor $\left(\mathrm{R}_{2}+\right) \quad 3 \%$

\section{0 \& 2011}

Total $(n=185+195)$

Do not externally review $\quad 59 \%$

Review externally $\quad \mathbf{4 0} \%$

First decision upon external review

$\begin{array}{lr}\text { Decline } & \mathbf{6 7 \%} \\ \text { Major revision } & \mathbf{1 9 \%} \\ \text { Minor revision } & \mathbf{1 1 \%} \\ \text { Conditional accept } & \mathbf{3 \%}\end{array}$

Final decision to date

Accept $\quad 5 \%$

Do not externally review $\quad 59 \%$

Decline upon review $\quad \mathbf{2 6 \%}$

Revise $\quad \mathbf{6 \%}$

Under Review (V1-R1) $\quad \mathbf{1 \%}$

With Editor $(\mathrm{R} 2+) \quad \mathbf{1 \%}$

Note: A comparison of data from the last volume-year against the last two volume-years indicates a slight decrease in the number of manuscripts declined upon the first set of external reviews (and a corresponding increase in the number that receive a "major revision"). We believe this is a reflection of our deliberate choice and continued effort to work with more authors over a longer period of time with the hope of developing the full potential of manuscripts. Other decision rates remain relatively steady. Total article submissions continue to show a positive trend $(2012=200)(2011=195)(2010=185)$. (Reflections pieces are excluded from data.

\section{BOOK REVIEW APPENDIX}

The Perspectives on Politics BOOK REVIEW received 1465 books in 2012 and identified 450 of them for review or treatment in one of our special formats. We contacted over 700 potential review authors, over 350 of which agreed to write a review, author a review essay, participate in a critical dialogue, or contribute to a book symposium. (Note: some of these have yet to appear in our pages.) 
Number of books treated in published single or multiple book reviews by section, 2012:

\section{Political Theory: 41 \\ American Politics: 42 \\ Comparative Politics: 50 \\ International Relations: 48}

\section{Cross-Disciplinary Sections: 117}

(Vol. 10, Issue 1) Religion and Politics: 12

(Vol. 10, Issue 2) Violence and Politics: 40

(Vol. 10, Issue 3) Post-Katrina New Orleans: (32)

Minority Politics: 12

Urban Politics: 6

Disaster and Recovery: 5

Private Power vs. Public Power: 9

(Vol. 10, Issue 4) Authoritarianism, Elections, Democracy: 33

The distribution of books treated in published, single or multiple book reviews is balanced across the traditional subfield divides. See pie chart, below.

\section{Books Treated in Published Reviews 2012 - by field/category}

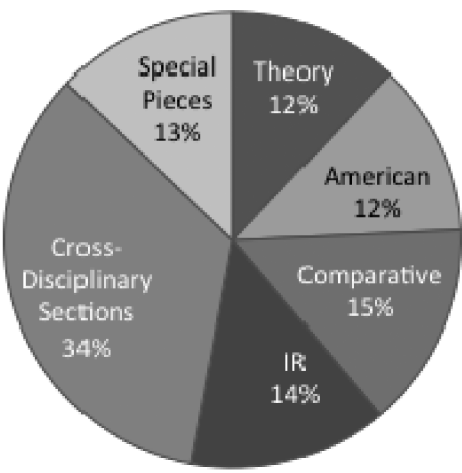

In addition to treatment in "traditional" reviews (listed above), 44 books were treated in special pieces (i.e. review essays, symposia, critical dialogues). For a full alphabetical listing of list of books treated, please see the "review index" provided in the appendix.

\section{APPENDIX CONTENTS}

Peer Review Appendix

- Manuscript success rates and comparison of review-stage data from 2012 versus prior years

Book Review Appendix

- Distribution of books reviewed by field

Links to Issue Front-matter

-10(1) Table of Contents

http://dx.doi.org/10.1017/S1537592711004932

-10(2) Table of Contents

http://dx.doi.org/10.1017/S1537592712000795

- 10(3) Table of Contents

http://dx.doi.org/10.1017/S1537592712001715

-10(4) Table of Contents

http://dx.doi.org/10.1017/S1537592712001739

Links to Review Indexes

-10(1) Review Index

http://dx.doi.org/10.1017/S1537592712000011
-10(2) Review Index

http://dx.doi.org/10.1017/S1537592712001211

-10(3) Review Index

http://dx.doi.org/10.1017/S1537592712002058

-10(4) Review Index

http://dx.doi.org/10.1017/S1537592712002770

Editor's Introductions

-10(1) Occupations, Preoccupations, and Political Science

http://dx.doi.org/10.1017/S1537592711004956

-10(2) New Approaches to the Study of Violence

http://dx.doi.org/10.1017/S1537592712000783

-10(3) A Perspective on Perspectives

http://dx.doi.org/10.1017/S1537592712001612

-10(4) Authoritarianism, Elections, Democracy?

http://dx.doi.org/10.1017/S1537592712002848 